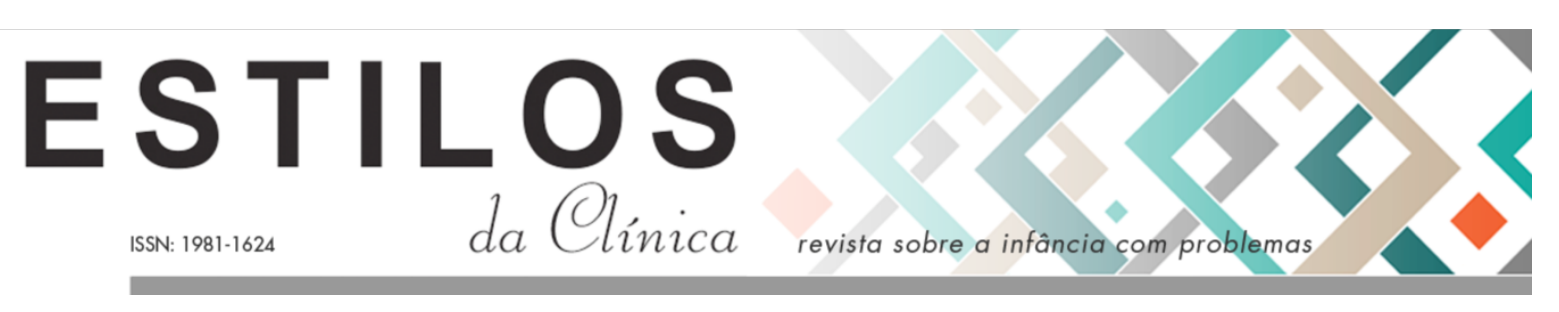

DOI: https://doi.org/10.11606/issn.1981-1624.v26i1 p83-98.

\title{
Artigo \\ Do acolhimento institucional à família adotiva: a vivência da criança nesta transição
}

\author{
Amanda Carollo Ramos da Silva; Jorge Luís Ferreira Abrão
}

Resumo. O presente artigo objetiva abordar, a partir da perspectiva psicanalítica, as vicissitudes de crianças, em transição do acolhimento institucional a uma família adotiva, dando especial atenção ao processo de vinculação à nova família. São apresentadas questões sobre a legislação e os trâmites processuais da adoção, e, em seguida, apresentados recortes da teoria psicanalítica sobre a vivência do abandono, da separação da família de origem, do luto e da formação de novos vínculos, situações comuns às crianças em adoção tardia. O método utilizado é o estudo de caso, no qual se busca elucidar a vivência de uma criança, em vias de adoção. A análise dos resultados aponta que a adotanda ainda não havia vivenciado o luto quanto à impossibilidade de seu retorno à sua família de origem, sendo interrompido o processo de aproximação com os pretendes à adoção. Aponta-se a necessidade da escuta e da preparação da criança para vivenciar o processo adotivo, avaliando sua condição e disponibilidade psíquica para ser inserida em uma nova família. Conclui-se que o fato de a criança estar juridicamente apta à adoção, não corresponde a estar emocionalmente pronta para essa mudança em sua vida. Evidencia-se, assim, a importância da atuação do psicólogo judiciário neste contexto.

Palavras chave: adoção tardia; vínculo; acolhimento institucional; família adotiva.

\section{Del acogimiento institucional a la familia adoptiva: la vivencia en la transición}

Resumen. Este artículo ilustra, desde la psicoanálisis, las vicisitudes de niños en transición de una institución de acogida a una familia adoptiva, prestando atención al establecimiento del vinculo con la nueva familia. Son presentados temas acerca de legislación y tramites del proceso de adopción, y, a continuación, son analizados extractos de la teoría psicoanalítica sobre la experiencia de abandono, de separación de la familia de origen, de duelo y de establecimiento de nuevos vínculos, situaciones comunes en adopción tardía. El método utilizado es el estudio de caso, en que se busca explicar las vivencias de una niña en proceso de adopción. El análisis de los resultados apunta que la adoptada aún no ha vivenciado el duelo por la imposibilidad de retorno a su familia de origen, interrumpiendo el proceso de acercamiento con la familia adoptante. Señalamos la necesidad de escuchar

*Psicóloga no Tribunal de Justiça do Estado de São Paulo, doutoranda em Psicologia na Faculdade de Ciências e Letras de Assis da Universidade Estadual Paulista Júlio de Mesquita Filho; Assis, São Paulo, Brasil. E-mail: amanda.carollo@unesp.br

** Professor associado e Livre Docente do Departamento de Psicologia Clínica da Faculdade de Ciências e Letras de Assis da Universidade Estadual Paulista Júlio de Mesquita Filho, Assis, São Paulo, Brasil. E-mail: abrao@assis.unesp.br 
y preparar a los niños para vivenciar el proceso de adopción, evaluando su condición y disponibilidad psíquica para insertarse en una nueva familia. Concluimos que el hecho de que el niño esté apto legalmente para la adopción no corresponde a que se encuentre listo emocionalmente para este cambio en su vida. La importancia de la actuación del psicólogo jurídico es evidenciada.

Palabras clave: adopción tardía; vinculo; acogida institucional; familia adoptiva.

\section{From institutionalization to an adoptive family: the child's experience in this transition}

Abstract. This article aims to demonstrate from the psychoanalytic viewpoint the fate changes for children in transition from the institutional dwelling to a foster family, emphasizing the binding process to the new family. Issues on the legislation, as well as the procedural steps for adoption are presented, and then aspects of the psychoanalytical theory on children experiencing abandonment, separation from the original family, mourning, and development of new affective relations, which are common issues to children in late adoption. The used method is the case study which provided the analysis of a child experience about to be adopted. The results indicate that the adoptee had not yet experienced the mourning as to the impossibility of returning to her biological family, which caused the interruption of the approximation with the applicant adoption family. This report points out the need for listening and preparing the child to experience the adoption process, the assessment of the child psychic condition and availability to be inserted into a new family. It is concluded that the fact the child is legally fit for adoption doesn't correspond to being emotionally ready for this change in life. Thus, the importance of judicial psychologist advice in this context is demonstrated.

Keywords: late adoption; affective relations; institutionalization; adoptive family.

\section{Du placement en institution à la famille d'accueil: l'expérience de l'enfant dans cette transition}

Résumé. Cet article vise à aborder, dans une perspective psychanalytique, les vicissitudes des enfants en transition entre le placement en institution et la famille adoptive, en accordant une attention particulière au processus d'attachement à la nouvelle famille. Des questions sur la législation et les procédures d'adoption sont présentées, puis des coupures de la théorie psychanalytique sur l'expérience de l'abandon, la séparation de la famille d'origine, le deuil et la formation de nouveaux liens, situations communes aux enfants en adoption tardive. La méthode utilisée est l'étude de cas, dans laquelle l'objectif est d'élucider l'expérience d'un enfant en cours d'adoption. L'analyse des résultats montre que l'enfant adopté n'avait pas encore vécu le deuil de l'impossibilité de son retour dans sa famille d'origine, étant interrompu le processus de rapprochement avec l'adoption envisagée. La nécessité d'écouter et de préparer l'enfant à vivre le processus d'adoption est soulignée, en évaluant son état et sa disponibilité psychique à être inséré dans une nouvelle famille. Il est conclu que le fait que l'enfant soit légalement apte à l'adoption ne correspond pas au fait qu'il soit émotionnellement prêt pour ce changement dans sa vie. Il est donc évident que l'action du psychologue judiciaire est importante dans ce contexte.

Mots-clés: adoption tardive; lien; placement en institution; famille adoptive.

$\mathrm{O}$ presente artigo tem como objetivo abordar, a partir da perspectiva psicanalítica, as vivências de crianças, em transição do acolhimento institucional a uma família adotiva, dando especial atenção ao processo de vinculação à nova família.

O interesse em debruçar-se sobre este tema surgiu com base na experiência de uma das autoras, que acompanhou, simultaneamente, em seu cotidiano profissional, o processo de aproximação entre seis crianças, em medida de proteção de acolhimento institucional, e as 
famílias pretendentes à adoção. Cabe posicionar que é a partir deste lugar, de psicóloga que atua no Poder Judiciário, que este relato de experiência se desenha.

A participação nestes casos suscitou diversas reflexões sobre a atuação em processos de adoção tardia ${ }^{1}$, cujos procedimentos se mostraram fragilizados, especialmente quanto à escuta de crianças e adolescentes para vivenciarem a adoção. Sendo assim, o artigo pretende trazer à luz as vicissitudes dos adotandos neste processo, utilizando-se do método de estudo de caso.

Para fins de organização deste trabalho, primeiramente serão tratadas questões a respeito do processo de adoção, incluindo pressupostos legais, reflexões sobre os trâmites processuais e preparação das crianças a passarem por esta transição. Na sequência, serão apresentados recortes da teoria psicanalítica sobre a vivência do abandono, da separação da família de origem, do luto e da formação de novos vínculos - situações comuns às crianças em adoção tardia - para então, com os devidos cuidados éticos, proceder ao relato e a uma possível análise de um processo de vinculação entre uma criança e seus pretendentes à adoção. Buscou-se estabelecer um diálogo entre o caso e os conteúdos teóricos apresentados.

\section{O processo de adoção e a preparação dos adotandos}

Tratar do tema adoção, neste contexto de crianças em situação de acolhimento institucional, remete em linhas gerais a um cenário, no qual, em sua família de origem, a criança teve seus direitos violados, e o Estado, fazendo o uso da Lei, considerando o melhor interesse desta criança, coloca-a em uma família adotiva.

No período de transição entre o afastamento da família natural e a colocação em uma nova família, a criança permanece em uma instituição de acolhimento. Estar acolhida configura-se como uma medida de proteção, que não ocorre, porém, isenta de sofrimento para os envolvidos e impactos na constituição da subjetividade da criança. Durante este período, é realizado um trabalho pela rede de serviços municipais, bem como pelo Poder Judiciário, com a família de origem da criança, visando à superação das situações que ensejaram o afastamento desta de seu núcleo familiar. Via de regra, o foco é possibilitar o fortalecimento dos vínculos e da capacidade protetiva da família, a fim de que a criança retorne ao seio familiar. No entanto, quando não se vislumbra tal perspectiva, visando ao melhor interesse da criança, é proposta a ação de destituição familiar, que rompe definitivamente sua vinculação jurídica com a família natural. No curso desta ação, alguns magistrados já determinam a busca de pretendentes que possam se interessar na adoção, podendo esta ser efetivada após a sentença da perda do poder familiar. No que se refere à família biológica, em geral, permanece o acompanhamento socioassistencial por meio dos serviços municipais. É neste cenário que se desenvolve o trabalho de psicólogos que atuam no Poder Judiciário, cujas atribuições profissionais envolvem acompanhar todas as etapas da adoção, desde o acolhimento institucional da criança até a efetivação do processo adotivo.

O Estatuto da Criança e do Adolescente (ECA), lei no 8.069 de 13 de julho de 1990, institui um conjunto de normas, visando à proteção dos direitos das crianças e dos adolescentes. No

\footnotetext{
${ }^{1}$ Adoção tardia é o termo utilizado para se referir à adoção de crianças maiores de dois anos de idade. Do ponto de vista jurídico, essa adoção configura-se como qualquer outra, porém, sua própria denominação especial remete à existência de particularidades no processo (Mendes, 2007).
} 
que se refere à adoção, a legislação prevê que seja precedida pelo estágio de convivência, por um prazo máximo de 90 dias (Brasil, 1990). Este período corresponde ao momento em que os pretendentes à adoção já detêm a guarda provisória da criança, e esta passa a viver junto a eles. Embora não esteja previsto em lei, antes de ser deferido o estágio de convivência, tem-se um período, especialmente em adoções de crianças maiores, com duração variável, a partir do qual se possibilita o estabelecimento da vinculação entre os adotandos e os adotantes. O processo só evolui para o estágio de convivência, quando se avalia que esta etapa inicial de aproximação se cumpriu de forma satisfatória.

O ECA prevê que a criança seja, sempre que possível, ouvida por equipe interprofisssional e tenha sua opinião considerada, levando em conta seu estágio de desenvolvimento e grau de compreensão sobre as implicações da medida. Estabelece que haja sua preparação ${ }^{2}$ gradativa para vivenciar esse processo de transição, além de prever um acompanhamento posterior, realizados por equipe da Vara da Infância e da Juventude. Quando adolescente, a partir dos 12 anos de idade, necessariamente deverá haver seu consentimento para aplicação da medida (Brasil, 1990).

Quanto aos pretendentes à adoção, a legislação brasileira também prevê uma preparação. A habilitação de pessoas interessadas na adoção é precedida por uma preparação psicossocial e jurídica, orientada pela equipe técnica da Justiça da Infância e da Juventude, além de avaliação psicossocial, que possibilite analisar aspectos sociais e psicológicos, relacionados à adoção e ao exercício da parentalidade (Brasil, 1990). A sentença de habilitação significa que o pretendente está apto à adoção e, a partir de então, quando houver a criança dentro do perfil desejado, a qualquer momento, poderá ser contatado para o início do processo de aproximação.

A percepção, enquanto psicóloga que atua no Poder Judiciário, é que a atuação dos profissionais está muito mais voltada para os adultos, pretendentes à adoção, do que para as crianças que vivenciarão tal processo, embora a legislação brasileira preveja que os técnicos judiciários tenham o olhar tanto para os adotandos quanto para os adotantes, na preparação de ambos, conforme apontado acima.

Peiter (2016), corroborando tal percepção, indica, a partir de levantamento bibliográfico quanto ao trabalho realizado com os adotandos, que "a preparação para adoção é uma prática ainda incipiente no Estado de São Paulo e na maior parte do Brasil." (Peiter, 2016, p. 77). Silva, Cassarino-Perez, Sarriera e Frizzo (2017), em pesquisa realizada com profissionais da equipe psicossocial do Judiciário do Rio Grande do Sul, apontam a falta de consenso sobre a forma como a colocação da criança em uma família adotiva deve ser conduzida, bem como sobre o papel de cada profissional neste contexto. Guimarães (2015), por sua vez, ao constatar a ausência de pesquisas acadêmicas com a participação dos adotandos, questiona como estaria se dando a participação das crianças nas práticas que permeiam o sistema de adoção no país. Observa que "o sistema de proteção brasileiro ainda está aprendendo a incluir a participação das crianças e adolescentes nas práticas cotidianas dos serviços.” (Guimarães, 2015, pp. 144 145).

Outra situação comumente vivenciada no cotidiano profissional no acompanhamento a casos de adoção, também apontada por Paiva (2004), é o descompasso entre o tempo cronológico, o tempo jurídico e o tempo psíquico da criança, devendo este último, ter especial atenção.

\footnotetext{
${ }^{2}$ Preparação é o termo utilizado na Lei no $8.069 / 1990$ (artigo $28, \S 5^{\circ}$ ).
} 
O papel dos operadores do direito é fazer as determinações legais, e o dos técnicos judiciários de cumpri-las. Se a criança está destituída do poder familiar (ou ainda em processo, dependendo do entendimento do magistrado) busca-se, do ponto de vista jurídico, colocá-la em uma família adotiva o mais rápido possível, como se ela já estivesse naturalmente "pronta" para vivenciar essa mudança. Muitas vezes, conforme aponta Mendes (2007), em caso de crianças maiores, "quando se decide por sua colocação na família adotiva, esta passagem tem ocorrido de forma bastante repentina e sem permitir o processamento de mudanças muito significativas para a constituição psíquica." (Mendes, 2007, p. 60). Silva et al. (2017) traz inclusive uma reflexão sobre o termo "colocação", utilizado nos processos adotivos, que em parte reforça o fazer mecânico no sistema judiciário e que põe a criança em uma posição objetificada.

Espera-se que a criança tenha o desejo de ir para uma família, e, normalmente, segundo Freitas (2017), esse é o sonho de uma criança institucionalizada, manifesto através da fala, de desenhos e brincadeiras. Defronta-se, porém, na prática profissional, com situações, principalmente em adoções tardias, nas quais a criança manifesta não querer sair da instituição de acolhimento e/ou não querer ir para uma nova família. Como lidar com essas situações? Essa negação seria uma defesa, a fim de evitar um novo abandono? Ou a criança ainda estaria vinculada psiquicamente à sua família, nutrindo a expectativa de, de fato, restabelecer esse vínculo?

Neste ponto, torna-se importante demarcar como concebemos a "preparação" da criança, considerando que a perspectiva psicanalítica trabalha com o a posteriori, isto é, as vivências do sujeito são significadas no só-depois. Preparar a criança, neste sentido, refere-se a intervir antecipadamente, uma vez que tenham sido identificados possíveis entraves subjetivos à vinculação com uma nova família. Há um deslocamento no qual o profissional passa de uma posição de espera para a posição de intervenção, pretendendo assim facilitar a constituição de novos arranjos psíquicos (Rosi \& Lucero, 2018).

Neste processo, a criança deve ser esclarecida de forma adequada sobre os motivos do acolhimento, sobre as perspectivas de retornar a sua família de origem ou sobre ir para outra família. Além de agir com sinceridade, conforme aponta Dolto (1985), os que lidam com a criança devem escutá-la - o que ela quer ou pode dizer a partir de sua ótica. A intervenção do psicólogo busca possibilitar a simbolização do sofrimento da criança e o reordenamento de sua história, assegurando-lhe sua posição de sujeito.

Torna-se relevante tratar também do conceito de adotabilidade, que se relaciona à disponibilidade interna da criança em estabelecer novos vínculos e se inserir em uma nova família. Mendes (2007) coloca a avaliação da adotabilidade como uma atribuição do profissional de Psicologia no trabalho com crianças acolhidas, devendo esta ocorrer antes de se iniciar a busca por pretendentes à adoção. Assim, a partir desta noção, tem-se respaldo para afirmar que o fato de a criança estar juridicamente apta para ser encaminhada a uma família substituta não significa que ela esteja, naquele momento, psicologicamente apta para tal.

No processo de escuta e preparação da criança para vivenciar a adoção, Souza e Casanova (2014) indicam algumas perguntas que devem ser respondidas:

A criança foi informada (se maior) das mudanças que terá em sua vida? Ela quer ser adotada por estes pais que lhe oferecem? Como estão os vínculos com a família anterior, com a Instituição? Como foi vivenciada e entendida a ruptura com a família de origem? Quais são suas carências afetivas? (Souza \& Casanova, 2014, p. 52) 
As mesmas autoras apontam que deverá ser respeitado o tempo do adotando, no qual ele poderá assimilar e elaborar a possibilidade de ir para uma nova família. Esse momento de adaptação pode ser lento, pois exige a reconstrução de laços afetivos e de seu mundo interior (Souza \& Casanova, 2014). O trabalho do psicólogo, nesta etapa que antecede a concretização da adoção, é, segundo Silva et al. (2017), de suma importância a fim de evitar uma transição descuidada, mesmo em casos aparentemente "simples".

Apresentadas as questões deste tópico, fica anunciada a complexidade da adoção, que envolve além de ritos legais e processuais, dimensões psíquicas, que devem ser consideradas, a fim de que o processo ocorra de forma assertiva. Apesar do sistema jurídico proceder a um apagamento dos vínculos legais entre a criança e a família de origem com o processo de destituição do poder familiar, reconhece-se que em nível psíquico este rompimento não ocorre. Neste giro, buscar-se-á na visão psicanalítica elucidar a vivência da criança em processo de adoção.

\section{Psicanálise e a criança em processo de adoção}

Pensar a criança em adoção remete, dentre outras questões, à separação da família de origem, ao abandono, ao rompimento de vínculos, ao luto e a uma capacidade de se vincular novamente. Tais situações são comuns à vivência da criança acolhida e encaminhada para a adoção, porém, a ressonância destes acontecimentos na estruturação psíquica pode ser relativizada, de acordo com a vivência de cada uma (Paiva, 2004).

A teoria e a produção de alguns autores em Psicanálise, desde Freud até psicanalistas contemporâneos, podem nos auxiliar a refletir sobre a adoção, a partir da perspectiva da criança. Serão, neste momento, apresentados recortes teóricos e realizadas correlações com o tema, que poderão ser retomados posteriormente na tentativa de se analisar um dos casos atendidos.

Freud, o precursor da Psicanálise, em "Luto e Melancolia" (1917/1996), analisa os movimentos psíquicos presentes em situações de perdas afetivas. $\mathrm{O}$ autor descreve o luto como uma reação à perda de um ente querido ou à perda de uma abstração que ocupou um lugar de um ente querido, considerando que sua vivência é natural em momentos de separações e rupturas. Freud entende que, na perda do objeto amado, a libido retira-se gradativamente das ligações com o objeto perdido, exigindo um trabalho psíquico do ego, que demanda tempo e energia. Neste período, não se considera possível que o indivíduo se ligue a um novo objeto de amor, o que significaria, para ele, substituir o objeto perdido. Todavia, quando o trabalho do luto se conclui, o ego fica outra vez livre e desinibido, portanto, apto a fazer novos investimentos.

Para Winnicott, psicanalista inglês, a vivência deste processo, tal como descrito por Freud (1917/1996), não ocorrerá em crianças muito pequenas, tendo em vista que estas ainda não têm uma organização psíquica preparada para elaborar a perda deste modo. Winnicott teve seus trabalhos direcionados à infância e contribuiu com o entendimento sobre as consequências psíquicas de uma ruptura de vínculo precoce para a criança. Alguns de seus conceitos serão apresentados a seguir.

O referido autor estudou a relação entre a mãe e o bebê, apontando para o papel primordial que o meio ambiente, aqui representado pela figura materna, tem na constituição psíquica da 
criança. A "mãe suficientemente boa" é capaz de se identificar e se adaptar às necessidades do bebê e, de acordo com Winnicott (1965/1983), "a mãe através de sua identificação com o lactente sabe como se sente, de modo que é capaz de prover quase exatamente o que o lactente necessita em termos de holding e provisão do ambiente em geral." (Winnicott, 1965/1983, p. 53). Assim, a criança poderá obter as satisfações apropriadas e vivenciar as angústias e ansiedades, sem receio de se desintegrar.

O conceito de "preocupação materna primária", também proposto por Winnicott (1956/1988), nesta linha, refere-se a essa intensa identificação da mãe com seu filho - um estado necessário para o desenvolvimento emocional da criança. Gradativamente, essa adaptação deve diminuir ao longo do processo de desenvolvimento, considerando o fortalecimento da capacidade da criança em tolerar frustrações. Nessa relação mãe e filho, sadia, o ego da criança é reforçado, ou seja, o indivíduo se torna capaz de desenvolver defesas e organizar padrões pessoais - a criança torna-se ela mesma.

Ao se pensar nas crianças acolhidas em instituições, fazendo uma correlação com os conceitos de Winnicott, pode-se entender, em um sentido mais ampliado, que, para serem afastadas do convívio familiar, houve uma falha importante neste ambiente original, que de alguma forma não conseguiu ser "suficientemente bom".

O mesmo pode ser elucidado quanto ao ambiente propiciado pela instituição de acolhimento. Por melhor que seja o trabalho realizado pelos profissionais do abrigo, não se pode compará-lo à vivência possibilitada ante a colocação da criança em uma família substituta. A premissa da adoção, nesta perspectiva, é que a nova família ofereça ao adotando este ambiente seguro e estável, a partir do qual a criança possa crescer, se identificar, olhar para sua história e ressignificá-la. (Otuka, Scorsolini-Comin \& Santos 2012).

Dependendo do tempo e do período em que há a privação dos cuidados maternos, ou em outras palavras, em que ocorre a falha ambiental, Winnicott (1965/1983) propõe diferentes quadros de patologias que podem se apresentar: dissociação esquizoide, patologias ligadas ao falso-self e a tendência antissocial. Para fins deste artigo, interessa-nos tratar sobre o falso-self, que é frequentemente identificado por estudiosos, segundo Mendes (2007), em casos de crianças adotivas.

O falso-self tem sua origem em uma etapa precoce do desenvolvimento, quando o bebê não recebe de sua mãe o reflexo daquilo que apresenta a ela, descontinuando seu ser. O falso-self tem como uma função a busca de continuidade e proteção ao verdadeiro self, de forma que o bebê materna a si mesmo. De acordo com Winnicott (1965/2011):

\footnotetext{
Se a maternagem não for boa o suficiente, a criança torna-se um acumulado de reações à violação; o self verdadeiro da criança não consegue formar-se, ou permanece oculto por trás de um falso self que a um só tempo quer evitar e compactuar com as bofetadas do mundo. (Winnicott, 1965/2011, p. 24)
}

Crianças que passaram pela vivência de separações precoces e do abandono podem desenvolver angústias e preocupações exacerbadas em serem aceitas pelo ambiente. A criança "verdadeira", temendo se expor, "esconde-se" sob o falso-self, a fim de evitar um novo abandono.

Bowlby, psicanalista britânico, contemporâneo a Winnicott, também direcionou seus estudos ao desenvolvimento infantil e à influência da relação da criança com a mãe - em sua 
presença e em sua ausência - dando destaque à importância das relações iniciais para o desenvolvimento saudável.

Bowlby (1973/1993a) postula que o relacionamento da criança com seus cuidadores, assim como a vivência de separações e perdas, influenciam no estabelecimento e na qualidade de relacionamentos futuros.

A Teoria do Apego, também chamada de Teoria da Vinculação, formulada por este autor, explica o processo de formação e de rompimento de vínculos afetivos. A criança desenvolve o apego à figura que está próxima e realiza os seus cuidados - em geral, a mãe - sendo esta fonte de segurança e proteção. É, assim, formada uma base segura, na qual a criança poderá experienciar o mundo, podendo retornar a este "porto seguro" diante de alguma ameaça.

Tinoco e Franco (2011), referenciando a teoria de Bowlby (1973/1993a), colocam:

\begin{abstract}
Em experiências de separação prolongada ou permanente, a criança é capaz de vincular-se a outras figuras e, quando também as perde, apresenta reações intensas. Porém, quando o processo de apegar-se e perder acontece muitas vezes, a criança vai se ligando cada vez menos, podendo não se apegar a mais ninguém, não reagindo às separações e reencontros. (Tinoco \& Franco, 2011, p. 429)
\end{abstract}

Continuam explicando que, diante dessa ausência de reação, a criança pode passar a impressão de estar adaptada ao meio, todavia, na realidade, essa seria uma forma de protegerse de novas perdas.

Em situações de abrigamento, Tinoco e Franco (2011) apontam que a criança experiencia múltiplos rompimentos, pois, em geral, ela não se encontra afastada apenas de sua família, mas também de seus pertences, hábitos e convívio social. Tal cenário é gerador de angústias e propicia o acionamento de comportamentos intensos de procura.

Bowlby (1980/1993b) coloca que a ameaça em perder a figura de apego levará a criança a uma reação na tentativa de proteger este vínculo, havendo um esforço para recuperá-la, que, de forma inconsciente, nunca se cessa totalmente.

Para o autor, o êxito de uma nova vinculação não depende do esquecimento do vínculo anterior, mas é facilitado quando as duas relações puderem se manter distintas e presentes. Apesar de não se considerar uma tarefa fácil, para a mãe substituta que ocupa o novo lugar na relação, Tinoco e Franco (2011) colocam que: "Se a criança sente que tem de fazer uma escolha que pode ameaçar sua relação anterior, é possível que resista a se adaptar às novas pessoas e novas circunstâncias de vida." (Tinoco \& Franco, 2011, p. 430)

Levinzon (1997), psicanalista brasileira que estuda o tema adoção, também aborda a questão da separação da criança de sua mãe natural, a qual muitas vezes traz uma configuração concreta de abandono, rompendo com um laço e um ritmo específico, que existe entre a mãe a criança desde a gestação. Em sua tese de doutorado, expõe e analisa as questões psíquicas da criança em adoção:

a angústia de separação e suas vicissitudes representam uma questão nuclear no equilíbrio psíquico do adotado. Os sentimentos de abandono, desamparo e a iminência de perda do objeto amado aparecem como um pano de fundo que influencia suas possibilidades de contato com o mundo interno, suas relações interpessoais e os mecanismos utilizados para sobrevivência e adaptação ao ambiente. (Levinzon, 1997, p. 260) 
A descontinuidade do vínculo, segundo a autora, é a base para uma sensibilidade maior diante de situações de separação, tornando-se futuramente um medo exacerbado de passar por um novo abandono.

O trabalho realizado por Goldenberg (1992) observa que sérios problemas são ocasionados pela privação de estimulação sensorial e pela separação súbita da mãe natural. Indicam ainda que quanto menor for a criança, ao ser adotada, maiores as chances de resgatarem os laços afetivos e encontrarem continência no ambiente.

Nas adoções, principalmente nas consideradas tardias, existe a probabilidade de a criança ter passado por mais situações de separações, nas quais seus vínculos foram descontinuados e não elaborados (Peiter, 2016). A própria transição da instituição de acolhimento à família adotiva remete a mudanças e despedidas, sendo importante um trabalho elaborativo, a fim de que esse processo não seja vivido pela criança como uma nova situação de abandono.

Ozoux-Teffaine (2004), citado por Peiter (2016), aponta que o desejo de uma nova filiação não surge repentinamente. Decorre da elaboração do luto em relação às imagos parentais originais, na qual os sentimentos de abandono serão contemplados, e da progressiva aproximação e vinculação aos novos pais.

A criança continuará em uma instituição de acolhimento até haver o encontro com a família adotiva, e este período intermediário é propício para o surgimento de intensas sensações de desamparo e insegurança (Levinzon, 1997). O desejo de adoção não é vivido pela criança sem o temor de estar abandonando seus vínculos antigos e sem o sentimento de culpa por estar deixando os demais na instituição de acolhimento. Percebe-se, então, que este processo é permeado por ambivalências, pois de alguma forma essa criança também teve afetos positivos decorrentes de tais ligações e convívios (Peiter, 2016).

Alvarenga e Bittencourt (2013) apontam que, em algumas crianças, concomitante ao desejo de adoção, há "uma idealização da família de origem juntamente com o esforço para conservar uma imagem positiva dos genitores." (Alvarenga \& Bittencourt, 2013, p. 43). Neste movimento, ao mesmo tempo em que poderá haver resistência em relação aos pais adotivos, a criança pode, como receio de não ser aceita, rapidamente assumir uma nova identidade.

Espera-se que os pretendentes à adoção sejam capazes de conter e acolher a criança, neste processo de mudança e adaptação, permitindo a vivência de suas ansiedades, e não se deixando ferir pelos comportamentos de enfrentamento por ventura apresentados por ela. Quando os adotantes não estão suficientemente preparados para lidar com a criança "real", ocorrem as situações denominadas de "devolução", na qual estes desistem do processo de adoção.

\section{Método}

Para atingir o objetivo de abordar sobre as experiências de crianças que vivenciam o processo de transição entre o acolhimento institucional e sua inclusão em uma nova família, articulando a teoria com a prática profissional, elegeu-se o estudo de caso como método.

Antes de falar propriamente sobre ele, é importante demarcar que, neste trabalho, se fala a partir da psicanálise aplicada, isto é, o método psicanalítico sendo utilizado fora da clínica tradicional. Aqui, especificamente, no âmbito da atuação do psicólogo no Poder Judiciário. Independente do contexto, tendo como referência o olhar psicanalítico, o que se busca é o 
conhecimento psíquico. Herrmann (2004) coloca que na clínica extensa, ou seja, nas formas ampliadas de se fazer psicanálise "também há pesquisa da psique, da psique individual e da psique social." (Herrmann, 2004, p. 27).

Feita tal consideração, passamos ao estudo de caso em psicanálise. Segundo Guimarães e Bento (2008), este método está relacionado à experiência clínica e à construção do sentido daquilo que ocorrera (ou não) no atendimento. Definem o estudo de caso como sendo a escrita da clínica analítica, incluindo não só a descrição, mas sua teorização, sendo um trabalho de pensamento por parte do analista, não mais sobre a prática em si, mas a partir dela.

Tais autores entendem que os estudos de caso não devem ser vistos "como ilustrações clínicas da teoria, mas sim, como possibilidade de se recorrer a clínica do caso como ponto de partida da construção, da aceitação e da refutação da teoria.” (Guimarães \& Bento, 2008, p. 96). Afirmam que vinhetas clínicas não objetivam provar a teoria, mas sim ilustrá-la. A função da teoria, de acordo com Mezan (1993), está relacionada a vincular a singularidade do caso à universalidade dos conceitos, buscando determinar, a partir da psicanálise, os processos psíquicos em jogo para produzir um ou outro fenômeno.

Considerando os apontamentos sobre o método, traremos, a partir da experiência profissional, o relato de um processo de aproximação entre uma criança e o casal pretendente à adoção, e uma análise da vivência desta criança nesta possibilidade de transição entre o acolhimento institucional e a nova família. Este caso, por ter um desfecho diferente dos demais processos acompanhados, trouxe à equipe uma inquietação e o ímpeto de aprofundar sua análise.

O contato com esta criança se deu pelo período aproximado de dois anos, desde o início de seu acolhimento, sendo diversos instrumentos utilizados nos atendimentos: entrevistas, observações lúdicas (tanto no ambiente da instituição de acolhimento, quanto nas dependências da instituição judiciária), aplicação da técnica projetiva do Desenho-Estória e do teste psicológico H-T-P. Foram também realizadas entrevistas com os familiares e discussões técnicas, envolvendo os serviços socioassistencias. Foi a partir destas intervenções que se obtiveram os dados, que serão descritos. Os devidos cuidados éticos foram tomados neste relato, a fim de se preservar o sigilo e, de modo fictício, chamaremos a adotanda de Melissa.

\section{Análise de um processo de aproximação: o caso de Melissa}

Melissa, oito anos de idade, era uma criança afetuosa, comunicativa e inteligente. Seu perfil destoava dos demais acolhidos - a situação de acolhimento, e as situações anteriormente vividas, aparentemente não haviam afetado seu desenvolvimento social e cognitivo. Todavia, mostrava indicativos de fragilidade emocional e tristeza, ao se abordar sobre a família. Demonstrava necessidade de segurança e de receber cuidados e afeto, parecendo reconhecer e entender que sua família de origem não vinha suprindo tais necessidades. Apesar disso, nutria expectativas em estar com a genitora e outros familiares, com quem, em alguns momentos, dizia querer morar. 
A mãe biológica ${ }^{3}$ de Melissa apresentava histórico de dependência química, e tinha-se conhecimento de que, desde o nascimento da criança, ela não havia de fato assumido os cuidados da filha, apesar de alguma forma ter se feito presente em sua vida. A avó foi quem exerceu a função materna e se responsabilizou pela criança até cerca de quatro anos de idade, quando veio a falecer. Neste contexto, havia a figura de outros familiares, que apoiavam financeiramente a genitora de Melissa, porém, que não se dispunham a assumir a responsabilidade de guarda da menina.

O conselho tutelar, que já vinha acompanhando o caso, aplicou a medida de proteção de acolhimento por acionamento de um familiar, que se recusava a permanecer com Melissa. $\mathrm{Na}$ ocasião, a menina estava com seis anos de idade, e, segundo relato dos conselheiros tutelares, a retirada de Melissa da residência foi uma situação de muito sofrimento para a criança.

Após aproximadamente um ano e meio de seu acolhimento, o contexto familiar que culminou com a medida de proteção, permanecia inalterado. Apesar das tentativas de reorganização de sua vida, a genitora não mostrava indícios de que poderia exercer os cuidados da filha. Os demais familiares se mantinham indisponíveis a assumir a guarda da criança ou, tampouco, manter uma vinculação afetiva. Assim, sem haver uma perspectiva favorável de Melissa retornar ao convívio familiar, o Ministério Público propôs a ação de destituição do poder familiar, acatada pelo Judiciário, que, de imediato, determinou a busca de pretendentes à adoção da menina. Em um primeiro momento, quando abordado a respeito da possibilidade de uma nova família, ela mostrou-se resistente, inclusive sugerindo que as técnicas judiciárias procurassem primeiro pais para as demais crianças acolhidas.

Passando alguns dias, em novo atendimento, Melissa verbalizou que gostaria sim de ser adotada. Iniciou-se a busca de interessados em sua adoção, sendo localizado um casal, cujo perfil de criança desejada correspondia ao da menina.

Surpreendentemente, o processo de aproximação entre o casal e a criança estava ocorrendo de forma bastante positiva, de forma que Melissa, após algumas semanas, começou a passar os finais de semana com os pretendentes, que residiam em outra cidade. A criança mantinha contato diário com o casal, já se referia a eles como seus pais, e, em seus desenhos, sempre os representava, dizendo que os amava. Já fazia planos e vislumbrava a mudança, referindo-se à nova casa, à nova escola e à festa de aniversário do ano seguinte.

Tanto a infante, quanto o casal, já verbalizavam a vontade de que passassem a morar juntos, e, considerando que a vinculação estaria ocorrendo dentro do esperado, o início do estágio de convivência já seria solicitado dentro de alguns dias, com a iminência do período de férias escolares.

Neste ínterim, a mãe biológica de Melissa, que até então estava com paradeiro desconhecido, foi até a instituição de acolhimento, sob aparente efeito do uso de substâncias psicoativas, verbalizando querer ver a filha. Não foi permitida sua entrada, porém, mesmo assim, a criança chegou a avistar a mãe.

A partir de então, os pretendentes observaram que Melissa passou a ter outros comportamentos diante deles, tratando-os de forma distante. Junto a eles, apresentou crises intensas de choro, pedindo para voltar para o acolhimento. Diante dos acontecimentos, o casal

\footnotetext{
3 Ao abordar sobre a genitora, pretende-se contextualizar o caso, não havendo a intenção de se ter um viés moralista. Tem-se um olhar global para sua história, reconhecendo as falhas sociais que permearam sua vida.
} 
pediu a interrupção do processo, colocando como motivador o fato de entender que a criança não estaria pronta para a adoção.

Caberia também proceder uma análise sobre se os pretendentes estariam de fato preparados para a adoção, no sentido de acolher a criança em suas angústias, respeitando sua individualidade, sua história de vida e seu tempo, no entanto, este não será o nosso foco.

Em atendimento posterior ao ocorrido, Melissa relatou de forma entristecida ter visto a mãe e querer "ir" com ela, não demonstrando ressentimentos quanto à interrupção da aproximação com o casal.

\section{Análise dos dados}

Um primeiro ponto a ser pensado refere-se à relação de Melissa com sua família de origem. Apesar da situação de negligência e de abandono, que a mantém em acolhimento institucional, a criança idealizava os familiares, havendo o desejo de que algum deles a retirasse de sua atual situação. Esse fato corrobora com o apontado por Vargas (2006), a partir de pesquisa orientada, que crianças, mesmo após um ano de abrigamento por maus-tratos, violências e já até destituídas do poder familiar, continuam a ter expectativas de retornarem à família de origem.

Sobre os primeiros anos de vida de Melissa, poucas informações são conhecidas, porém, por sua condição de desenvolvimento, supõe-se que suas relações iniciais foram positivas, havendo um ambiente seguro e estável, que proporcionou seu apego a uma figura maternal, não necessariamente à mãe biológica. Conforme apontado, sabe-se que a genitora não foi a agente destes cuidados, porém, possivelmente a avó tenha exercido esse papel, descrito por Bowlby (1973/1993a,1980/1993b). Pode-se hipotetisar que inicialmente, recorrendo à teoria de Winnicott, o ambiente foi suficientemente bom, o que proporcionou o desenvolvimento saudável de Melissa. De acordo com este autor:

mesmo uma criança privada da vida familiar pode ter vivido em condições favoráveis na primeiríssima infância, e pode até ter experimentado por certo tempo a vida em família. Num tal caso, as fundações da saúde mental da criança podem ter sido devidamente lançadas, tendo a doença sobrevindo a um panorama de saúde. (Winnicott, 1965/2011, pp. 200 - 201)

No caso de Melissa, considerando o histórico acessado, pode-se pensar que, atrelado ao falecimento da avó - sua cuidadora, instalou-se a "falha ambiental". Em meio a este novo contexto, começaram a se evidenciar indícios de que a criança estava sendo negligenciada em seus direitos e necessidades afetivas e de cuidado, o que culminou com a medida de proteção do acolhimento.

Fazendo referência ao apontado por Paiva (2004) quanto ao descompasso entre o tempo jurídico, tempo cronológico e tempo psíquico da criança, neste caso, pode-se pensar que, por parte dos operadores do direito, a preocupação maior era em relação ao tempo cronológico, pois Melissa estava crescendo, e com o passar do tempo, supostamente, cada vez mais seria dificultada sua adoção, em decorrência de sua idade. Assim, os processos de destituição e adoção foram operados paralelamente. Neste curso, no entanto, negligenciou-se, de certa forma, a elaboração psíquica de Melissa para vivenciar essa transição. Remeteu-nos aqui o apontado 
por Mendes (2007) em relação a adoções tardias: a colocação da criança na família adotiva muitas vezes ocorre sem que tenha havido o processamento psíquico de tal mudança.

De acordo com Vargas (2006), "as resistências, as dúvidas dos abrigados precisam ser respeitadas, o que não costuma ocorrer no âmbito das instituições, que também não oferecem continente para expressão do luto das perdas sofridas." (Vargas, 2006, p.159).

Apesar de estar vedado o contato com sua família de origem, percebia-se que para a criança ainda estava forte e presente a representação de seus familiares. Ao mesmo tempo, os comportamentos de Melissa apontavam positivamente à vinculação com o casal pretendente à adoção.

Pode-se propor, neste momento, uma relação com o conceito de falso-self, não necessariamente, na experiência da adotanda, tal como proposto por Winnicott (1965/2011), desenvolvido em suas relações iniciais, como uma ausência do reflexo materno. Mas, no sentido de que, na vinculação com os novos pais, ela demonstrou se adaptar muito rapidamente, talvez como um mecanismo para ser aceita e não ser novamente abandonada. Conforme aponta Levinzon (2018), as crianças adotivas "se preocupam em demasia em agradar aos pais e corresponder ao que lhes parece que esperam dela." (Levinzon, 2018, p. 49). Melissa se tornou, neste período, "outra” criança.

Pode-se analisar que a adotanda estava sim se vinculando ao casal, contudo, na concretude, na presença real da genitora, o processo se interrompeu. Ao ver a mãe, entre nutrir expectativas de estar junto à sua família de origem ou continuar com o novo casal, Melissa fez a primeira opção. Conforme aponta Bowlby (1980/1993b), mesmo que inconscientemente, a criança reagirá na tentativa de proteger o vínculo com a figura de apego, empenhando um esforço para recuperá-lo. Também, retomando Tinoco e Franco (2011), no que se refere ao processo de vinculação, possivelmente Melissa não tenha conseguido conciliar psiquicamente a relação com o casal adotivo e com a mãe biológica, sentindo que escolher a adoção ameaçaria o vínculo com sua família de origem.

Pode-se pensar, diante destas questões, que a criança ainda estava em processo de elaborar o luto quanto à impossibilidade de retorno à genitora, não estando seu ego "livre e desinibido" para novas ligações afetivas. O processo de transição, como era de se esperar partindo-se da ética psicanalítica, estava sendo permeado por ambivalências e, retomando Peiter (2016), com o receio significativo de estar abandonando sua família de origem e também seus vínculos do acolhimento.

Inclusive, cabe lembrar que juridicamente a criança ainda não estava apta para adoção, em decorrência do processo de destituição do poder familiar não estar sentenciado. Apesar de se entender que as chances de reversão deste processo eram mínimas, analisa-se o quanto o fato deste ainda não estar concluso pode ter refletido na dinâmica psíquica da criança, na busca e na esperança por essa família.

Retoma-se aqui a importância de, durante o período de acolhimento, se haver o acompanhamento psicológico da criança, através do qual ela possa olhar para sua história, ressignificá-la e dispor-se a novas relações. Todo o processo descrito ocorreu sem que fossem proporcionados a Melissa atendimentos clínicos que a apoiassem neste momento, o que nos faz pensar que, talvez, a vinculação com o casal tivesse tido um curso diferente, caso a menina já estivesse em processo terapêutico. 
A experiência profissional, envolvendo o acompanhamento dos processos de adoção, especialmente deste caso, que teve seu curso interrompido, tornou evidente a indissociabilidade do desejo da criança e de sua disponibilidade para integrar uma nova família. Entendida como sujeito de direitos, a criança deve ser vista em sua singularidade - se trabalhamos com a sua escuta, é preciso dar-lhe a voz e compreender em que momento ela se encontra. Muitas vezes, já estará "desligada" juridicamente da família de origem, mas, psiquicamente, ainda não estará disponível a novas relações.

\section{Considerações finais}

A adoção, mais especificamente o processo de vinculação da criança que está em situação de acolhimento institucional a uma nova família, é permeada por uma complexidade de sentimentos e vivências, de modo que nem sempre este processo ocorre de forma tranquila, isento de ansiedades e angústias. Em casos de adoções tardias, as crianças passaram pela separação da família de origem, pelo abandono, e, o desejo de uma nova filiação é construído gradativamente, à medida que é proporcionada a elaboração quanto às imagos parentais, possibilitando que a relação com a família biológica seja ressignificada e mantenha-se, de alguma forma, preservada psiquicamente.

No caso apresentado, analisou-se que a criança ainda não havia vivenciado o luto quanto à impossibilidade de seu retorno à sua família de origem. Assim, a vinculação com o novo casal, que inicialmente pareceu ocorrer de forma positiva, foi interrompida repentinamente, em decorrência de a criança ainda nutrir expectativas significativas em relação à sua família.

A adoção envolve uma escolha mútua entre a criança e os adultos pretendentes, e ambos devem ser acompanhados nessa vivência do processo adotivo. Neste artigo, pretendeu-se olhar para essa criança, indicando a importância de se escutá-la e de se avaliar sua condição e disponibilidade psíquica para ser inserida ou não em uma nova família.

Conforme apontado no decorrer deste trabalho, o fato de estar juridicamente apta à adoção não significa que a criança esteja emocionalmente pronta para essa mudança em sua vida. Neste contexto, a intervenção do psicólogo é essencial no acompanhamento das crianças em acolhimento institucional, a fim de que sejam ouvidas, consideradas em sua singularidade e preparadas para vivenciarem a adoção.

No entanto, é importante apontar que as práticas do psicólogo judiciário, neste contexto, ainda carecem de uma construção sistemática e articulada com os assistentes sociais judiciários e demais profissionais que compõe a rede socioassistencial, que também são responsáveis pelo acompanhamento destas crianças.

\section{Referências}

Alvarenga, L. L. \& Bittencourt, M. I. G. F. (2013). A delicada construção de um vínculo de filiação: o papel do psicólogo em casos de adoção. Pensando famílias, 17(1), 41 - 53. Recuperado de http://pepsic.bvsalud.org/scielo.php?script=sci_arttext\&pid=S1679494X2013000100005 
Brasil. (1990). Lei $n^{o} 8069$, de 13 de julho de 1990. Dispõe sobre o Estatuto da Criança e do Adolescente e dá outras providencias. Recuperado de http://www.planalto.gov.br/ccivil_03/Leis/L8069.htm

Bowlby, J. (1993a). Separação: angústia e raiva (L. Hegenberg, M. Hegenberg, O. S. Mota, trads.). São Paulo: Martins Fontes. (Trabalho original publicado em 1973).

Bowlby, J. (1993b). Perda, tristeza e depressão. (W. Dutra, trad.). São Paulo: Martins Fontes. (Trabalho original publicado em 1980).

Dolto, F. (1985). Seminário de psicanálise de crianças. (V. Ribeiro, trad.). Rio de Janeiro: Zahar.

Freitas, C. (2017). Criança institucionalizada: a importância da preparação na vivência do processo de adoção. Psicologia.pt. Recuperado de https://www.psicologia.pt/artigos/textos/TL0406.pdf

Freud, S. (1996). Luto e melancolia. In S. Freud, Edição standard das obras psicológicas completas de Sigmund Freud. (Vol. 14, J. Salomão, trad., pp. 245-263). Rio de Janeiro, RJ: Imago. (Trabalho original publicado em 1917).

Goldenberg, G. W. (1992). A adoção e a lei: um recorte da trama manifesta e da trama latente da vivência de abandono. Revista Brasileira de Psicanálise. 2(1), 23 - 9.

Guimarães, L. A. (2015). Escuta da criança no processo de adoção: procedimentos e direitos. In: F. Scorsolini-Comin, A. Pereira \& M. Nunes (Orgs.), Adoção: legislação, cenários e práticas (pp. 125-147). São Paulo: Vetor.

Guimarães, R. M. \& Bento, V. E. S. (2008). O método do "estudo de caso" em psicanálise. Psico, 39(1), $\quad 91-\quad 99 . \quad$ Recuperado de http://revistaseletronicas.pucrs.br/ojs/index.php/revistapsico/article/view/1484

Herrmann, F. (2004). Pesquisa Psicanalítica. Ciência e cultura, 56 (4), 25-28. Recuperado de

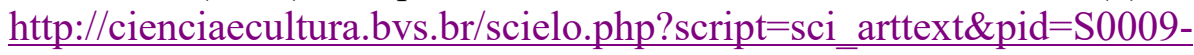
$\underline{67252004000400014}$

Levinzon, G. K. (1997). A criança adotiva na clínica psicanalítica. Tese de doutorado, Instituto de Psicologia, Universidade de São Paulo, São Paulo, SP.

Levinzon, G. K. (2018). Adoção e falso self: o dilema do "bom adotado". In G. Levinzon, \& A. Lisondo (Orgs.), Adoção: desafios da contemporaneidade (pp. 49 - 70). São Paulo: Blucher.

Mendes, C. L. P. C. (2007). Vínculos e rupturas na adoção: do abrigo para a família adotiva. Dissertação de mestrado, Instituto de Psicologia, Universidade de São Paulo, São Paulo, SP.

Mezan, R. (1993). Que significa pesquisa em psicanálise? In M. Silva (coord.), Investigação e psicanálise (pp. 49 - 89). Campinas, SP: Papirus.

Otuka, L. K., Scorsolini-Comin, F. \& Santos, M. A. (2012). Adoção suficientemente boa: experiência de um casal com filhos biológicos. Psicologia: Teoria e Pesquisa, 28(1), 55 63. doi: 10.1590/S0102-37722012000100007

Paiva, L. D. (2004). Adoção: significados e possibilidades. São Paulo: Casa do Psicólogo.

Peiter, C. (2016). Adoção: vínculos e rupturas: do abrigo à família adotiva. São Paulo: Zagodoni. 
Rosi, F. S. \& Lucero, A. (2018). Intervenção precoce x Estimulação precoce na clínica com bebês. Tempo psicanalítico, 50(1), 174-193. Recuperado de http://pepsic.bvsalud.org/pdf/tpsi/v50n1/v50n1a09.pdf

Silva, P. S., Cassarino-Perez, L., Sarriera, J. C. \& Frizzo, G. B. (2017). A Equipe Psicossocial na Colocação da Criança nos Processos de Adoção. Psicol., Ciênc. Prof., 37(3), 608623. doi: 10.1590/1982-3703000382016

Souza, H. P. \& Casanova, R. P. S. (2014). Adoção e a preparação dos pretendentes: roteiro para o trabalho nos grupos preparatórios. Curitiba, PR: Juruá.

Tinoco, V. \& Franco, M. H. P. (2011). O luto em instituições de abrigamento de crianças. Estudos de Psicologia (Campinas), 28(4), 427 - 434. doi: 10.1590/S0103166X2011000400003

Vargas, M. M. (2006). Adoção de crianças maiores. In: L. Filho \&S. Schettini (Orgs.), Adoção: os vários lados dessa história (pp. 147 - 171). Recife, PE: Bagaço.

Winnicott, D. W. (1956). Preocupação materna primária. In: D. Winnicott (1988). Textos selecionados: Da Pediatria à Psicanálise. (J. Russo, trad., pp. 491 - 498, 4a ed.). Rio de Janeiro, RJ: Francisco Alves.

Winnicott, D. W. (1983). O ambiente e os processos de maturação. (I. C. S. Ortiz, trad.). Porto Alegre, RS: Artes Médicas. (Trabalho original publicado em 1965).

Winnicott, D. W. (2011). A familia e o desenvolvimento individual. (M. B. Cipolla, trad., 4a ed.). São Paulo, SP: Martins Fontes. (Trabalho original publicado em 1965).

Revisão gramatical: Amanda Carollo

E-mail:amanda.carollo@unesp.br

Recebido em junho de 2020 - Aceito em janeiro de 2021. 